Linguagem em (Dis)curso - LemD, v. 8, n. 3, p. 519-539, set./dez. 2008

\title{
AVANÇOS E RETROCESSOS NAS PROPOSTAS DE ENSINO DE LÍNGUA PORTUGUESA: QUESTÕES DE IDEOLOGIA E DE PODER
}

Maria Sílvia Cintra Martins*

Resumo: Chamamos neste artigo a atenção para as questões de ideologia e de poder de cuja influência freqüentemente não nos damos conta, embora estejam sempre presentes nos contextos cotidianos de sala de aula, atravessando-os. Temos como principal objetivo alertar para os vetores que exercem pressão sobre a atuação do professor. Detemo-nos em considerações a respeito dos diferentes guias curriculares para o ensino de Língua Portuguesa. Discutimos de que forma as diretrizes recentes adotadas pela Secretaria da Educação do Estado de São Paulo, na forma dos "Cadernos do Professor", representam um retrocesso histórico em função de certos componentes ideológicos e hegemônicos que comportam.

Palavras-chave: língua materna; ensino; poder; ideologia; trabalho; docência.

\section{INTRODUÇÃO}

O trabalho que apresentamos é resultado de análises, reflexões e discussões que vimos empreendendo, no âmbito do Grupo de Pesquisa "Letramento do Professor" (Diretório Cnpq), particularmente após a publicação recente de uma série de "Cadernos do Professor" elaborados pela Secretaria da Educação do Estado de São Paulo (SÃO PAULO, 2008a). Por um lado, buscamos trazer contribuições a respeito de questões que estão implicadas no processo de ensino e aprendizagem de língua materna; por outro, trazemos reflexões sobre a formação e o

\footnotetext{
* Professora do Departamento de Letras da UFSCAR. Líder do Grupo de Pesquisa "Ethos, linguagem e construção da identidade" (Cnpq) e pesquisadora vinculada ao Grupo de Pesquisa "Letramento do Professor" (Diretório Cnpq). Doutora em Lingüística Aplicada. E-mail: <msilviam@ufscar.br>.
} 
letramento do professor de Língua Portuguesa que hoje atua na rede pública de ensino. Visamos, ainda, contribuir para a reconstituição histórica das diferentes tentativas de normatização do ensino da Língua Portuguesa por parte das instâncias governamentais e, com esse propósito, focalizamos diferentes propostas de ensino de Língua Portuguesa publicadas nos últimos trinta anos e efetuamos ponderações a respeito do retrocesso histórico que têm representado algumas iniciativas governamentais recentes.

\section{DIFERENTES PROPOSTAS E DIRETRIZES CURRI- CULARES}

A Proposta Curricular de Língua Portuguesa do Estado de São Paulo foi publicada em 1986, após um período de ampla discussão entre professores da rede pública de ensino desse estado. Até então, a referência para o ensino de língua materna era o chamado "Verdão" (BRASIL, 1975), documento que já comportava profundas inovações, sejam metodológicas, no que implica a relação entre corpo docente e discente, sejam nos fundamentos epistemológicos propriamente ditos, que passavam a apontar para a relativização da ênfase que costumava ser atribuída ao ensino da norma padrão e do registro escrito. ${ }^{1}$

Já havia, de toda maneira, um profundo descompasso entre a cultura escolar, ou seja, entre as representações e práticas que efetivamente circulavam no âmbito das instituições de ensino de primeiro e segundo graus (tanto públicas, quanto privadas) e as normatizações, prescrições ou referenciais advindos das instâncias administrativas e, indiretamente, da academia. Entre outros aspectos, o "Verdão" comportava a legitimação da linguagem oral e trazia propostas de trabalho com a oralidade em sala de aula, através de mesas-redondas, seminários, debates, círculos de conversa - que ainda não desfrutavam, no entanto, de um tratamento sob o enfoque dos gêneros do discurso, atualmente presente no PCN de Língua Portuguesa. É certo, de toda forma, que um professor de Língua Portuguesa - que tivesse se formado nos últimos anos da ditadura militar e que alimentasse ideais inovadores

\footnotetext{
1 "Guias Curriculares Nacionais", publicados no início da década de setenta e conhecidos pelos professores como "Verdão".
}

MARTINS - Avanços e retrocessos nas propostas de ensino... 
- poderia estranhar, já nessa época, que, apesar das inovações provindas das esferas governamentais, ainda predominasse fortemente no ambiente escolar a tendência ao ensino de viés clássico, vulgarmente conhecido como "ensino tradicional": centrado no letramento de prestígio de que o professor, em princípio, seria o detentor e no ensino de uma Língua Portuguesa ideal, normatizada por regras prescritas na Nomenclatura Gramatical Brasileira (NGB). Paradoxalmente, as prescrições ou referenciais advindos das instâncias administrativas eram portadores, assim, de um viés muito mais ousado, moderno ou avançado do que a cultura praticada nas escolas sob a guarda do professor.

No ano de 1985, houve ampla discussão nas escolas públicas a respeito dos rumos da educação: os professores foram chamados a discutir e, eventualmente, referendar as Propostas Curriculares que estavam sendo gestadas. Mesmo que se pudesse questionar a genuína representatividade democrática presente nesse momento histórico, o certo é que os professores foram então convidados a discutir previamente os pressupostos epistemológicos do documento oficial que estava para ser implantado e, quando este chegou às escolas, veio com o estatuto de uma proposta: não havia prescrição, não havia normatização ou, se havia, dava-se de forma essencialmente aberta, dialógica, marcada pela possibilidade da contradição.

A Proposta Curricular de Língua Portuguesa do Estado de São Paulo (SÃO PAULO, 1986) teve à sua frente lingüistas da estatura de Carlos Franchi. O caderno "Criatividade e gramática" (SÃO PAULO, 1988), de sua autoria, publicado logo em seguida, assim como os pequenos cadernos verdes de subsídios à implantação dessa proposta, trazem todos reflexões de lingüistas. Vale, aqui, mencionar a ênfase particular atribuída por Franchi ao trabalho epilingüístico e sua postulação das três vertentes no trabalho com a língua materna: atividades de linguagem, atividades de reflexão sobre a linguagem e atividades com a metalinguagem. Pela primeira vez em documentos oficiais, era feita essa distinção nítida das diversas abordagens do material lingüístico - o que já estava, à sua maneira, presente no documento anterior (BRASIL, 1975), porém sem essa delimitação clara e, principalmente, sem essa compreensão de que havia algo que não era nem propriamente produção ou interpretação de textos no sentido convencional, nem trabalho com nomenclatura gramatical. 
Franchi referia-se à linguagem como algo plástico e flexível, sujeito ao trabalho, à manipulação, mesmo à distorção por parte do sujeito falante. Vinha à tona, juntamente com isso, um novo enfoque a respeito do que se poderia entender por "Gramática" e de como se deveria, sim, trabalhar com Gramática dentro da sala de aula de Língua Portuguesa, sem que isso implicasse, necessariamente, a menção a nomenclatura metalingüística:

Chamamos de atividade epilingǘstica a essa prática que opera sobre a própria linguagem, compara as expressões, transforma-as, experimenta novos modos de construção canônicos ou não, brinca com a linguagem, investe as formas lingüísticas de novas significações. Não se pode ainda falar de 'gramática' no sentido de um sistema de noções descritivas, nem de uma metalinguagem representativa como uma nomenclatura gramatical. Não se dão nomes aos bois nem aos boiadeiros. O professor, sim, deve ter em mente a sistematização que lhe permite orientar e multiplicar essas atividades. (SÃO PAULO, 1988, p. 36)

Doze anos depois, foram publicados os PCNs, parâmetros curriculares nacionais. O PCN de Língua Portuguesa (BRASIL, 1998) era, em parte, resultado dos avanços presentes, principalmente, nas propostas curriculares dos estados de São Paulo e de Minas Gerais, porém com a assimilação das novidades advindas da Escola de Genebra com relação aos gêneros do discurso. Embora seja inegável o avanço que comportava, ao apresentar em nível nacional uma proposta de ensino de Língua Portuguesa de viés enunciativo-discursivo, em suas linhas, aparece, de modo mais ou menos explícito, a tendência para a didatização ou para a escolarização dos gêneros do discurso, algo que não se coaduna, por princípio, com a teorização de base bakhtiniana que daria sustentação, seja a essa própria proposta, seja aos pressupostos da Escola de Genebra (SCHNEUWLY, 2004; SCHNEUWLY; DOLZ, 2004). Sabemos, como veremos adiante, que Bakhtin (1997) postula, para os gêneros do discurso, uma maleabilidade, uma flexibilidade ou instabilidade equivalente àquela prevista por Franchi para o próprio funcionamento da linguagem. Nesse sentido, ou seja, naquele de uma tendência à re-estabilização do fato lingüístico e, conseqüentemente, a sua idealização, o PCN de Língua Portuguesa comportava um retrocesso. Aliás, também no sentido de chegar às escolas na forma de parâmetro 
advindo das instâncias administrativas, e não de proposta previamente discutida, mesmo que de forma mínima, entre os professores.

Já as recentes prescrições provindas da Secretaria de Educação do Estado de São Paulo (SÃO PAULO, 2008a), por sua vez, na forma de jornais de revisão e, em seguida, de cadernos bimestrais a serem seguidos pelos professores em seu trabalho de sala de aula - referimo-nos, aqui, a medidas administrativas governamentais do primeiro semestre letivo de 2008 - representam, em nosso entender, um passo ainda mais para trás. Trata-se de um retrocesso histórico, seja em função da imposição de normas sem o convite à discussão e à reflexão por parte do professor, seja pelo abandono daquilo que havia de mais profundamente linguageiro naquela proposta estadual de mais de vinte anos atrás - com sua ênfase na produção da atividade lingüística mais espontânea, e não no produto ou na tendência à padronização.

Nos itens que se seguem, pretendemos avançar algumas considerações teóricas que permitam uma compreensão mais clara do sentido pelo qual entendemos que vivemos um momento histórico de marcado retrocesso, no que diz respeito, em particular, às questões que apenas esboçamos nesta introdução.

\section{DO LETRAMENTO RESTRITO E DAS QUESTÕES DE PODER ${ }^{2}$}

Dos diversos pontos que mencionamos acima, acreditamos que merece um primeiro destaque aquele que diz respeito ao descompasso existente entre as prescrições advindas das instâncias administrativas - e, indiretamente, da academia - e o trabalho efetivo do professor em sala de aula.

Há uma pressuposição mais ou menos explícita, por parte de porta-vozes das instâncias administrativas e, muitas vezes, também de

\footnotetext{
2 Vale notar que, bem ora exploremos, neste item, o conceito de "letramento restrito", não nos alinhamos com a abordagem de Goody e de outros estudiosos como Olson (1997), por exemplo, que entendem o letramento de forma relativamente independente ou autônoma com relação às condições sócio-históricas em que é praticado. Nesse sentido, sentimo-nos próximos de Collins \& Blot (2005) que retomam conceitos desenvolvidos por Goody atribuindo-lhes uma visada sóciohistórica.
} 
pesquisadores nas universidades, de que o professor que hoje trabalha nas escolas públicas alimenta uma visão endemicamente tradicionalista, de que ele é resistente ou avesso às inovações e de que, em última instância, ele seria o grande culpado pelo fato de que, por melhores que tenham sido as diversas propostas ou normatizações, sempre foram precariamente implantadas. Ou seja: as academias e secretarias diversas estariam cheias de boas intenções, mas haveria algo na formação do professor que resiste - entendendo-se, de toda forma, a resistência como algo negativo - e torna a escola, em certo sentido, impermeável às tentativas de modernização. Outra vOz - proveniente de sindicatos da categoria e muitas vezes engrossada por vozes da universidade - advoga, por sua vez, que a falha deveria ser atribuída à falta de condições mínimas para o trabalho pedagógico, seja em função da baixa remuneração, da jornada de trabalho excessiva ou, ainda, do número excessivo de alunos em sala de aula. No embate, uns culpam os outros e há quem postule que mesmo se contempladas todas as condições infraestruturais inerentes à instituição escolar, mesmo assim seria insuficiente ou precário o trabalho do professor, em função - de volta ao mesmo argumento - de sua formação limitada ou inadequada.

Esboçaremos, aqui, uma outra suposição, embasada em abordagem sócio-histórica mais ampla que se alinha com a forma de análise própria dos assim chamados "Estudos do Letramento", ao considerar fatores existentes para além da instituição escolar de forma isolada, ou de uma comunicação que se daria de forma simples, entre as instâncias administrativas, as academias e o professorado. ${ }^{3}$

Conforme entendemos a questão, é preciso tecermos uma reflexão mais abrangente a respeito da forma de circulação da cultura ou da informação em nossa sociedade, algo a que o lingüista inglês Norman Fairclough (2001) se refere nos termos da produção, circulação e consumo de gêneros do discurso e que se dá, em princípio, no âmbito das práticas discursivas, recebendo e projetando influências sobre as esferas das práticas sociais (a macro-estrutura social dotada de componentes ideológicos e hegemônicos) e das práticas textuais mais

\footnotetext{
3 Aproveitamos para lembrar que Street (1993) faz diversas vezes menção a um divisor de águas que diferencia a tendência presente nos Estudos do Letramento ("New Literacy Studies"), com sua ênfase sócio-histórica, de outras abordagens a respeito do letramento: trata-se da maneira mais ampla com que o contexto é considerado.
}

MARTINS - Avanços e retrocessos nas propostas de ensino... 
pontuais (seja, no caso que nos interessa aqui, a instância da aula propriamente dita). É assim que, só aparentemente, a interlocução entre as secretarias e/ou a academia, por um lado, e a instituição escolar, por outro, se daria de forma direta ou mais imediatamente visível. Ou seja, parece, para os mais desavisados, que haveria a possibilidade de uma comunicação direta entre os ditames presentes nos parâmetros curriculares, por exemplo, e o professor de Língua Portuguesa que se relaciona cotidianamente com o corpo discente de ensino Fundamental e Médio.

Ao chamarmos a atenção para a forma da circulação da cultura letrada em nossa sociedade, desejamos apontar para questões de ideologia e de poder, enfatizando o caráter limitado dessa circulação, algo que nos faz apontar para o letramento restrito típico de sociedades ditas tradicionais, como as da Índia ou da África (cf. GOODY, 1968), e ainda presente, em grau ainda a ser mais bem compreendido, em nossa sociedade. Por um lado, dizemos que se trata de uma cultura letrada, pois vivemos numa sociedade eminentemente letrada, de tal forma que cabe alertar que mesmo a comunicação oral - principalmente aquela que circula em instituições escolares - é portadora de traços da cultura letrada; por outro, alertamos para a prática restrita ou limitada de certas formas desse letramento, uma vez que identificamos, em nosso meio, alguns resquícios daqueles traços característicos das sociedades tradicionais e de sua forma ou dimensão de letramento: recurso a estilo formulaico; tendência ao conhecimento hermético ou, de toda forma, a uma circulação restrita da cultura letrada de prestígio; persistência de modos orais de instrução; ênfase na aprendizagem de conteúdos memorizados de forma decorada; persistência de resíduos orais na cultura letrada; tendência ao preciosismo; apelo a concepções mágicoreligiosas; cultura escrita que mantém forte relação com a religiosidade. Vale lembrar que todas essas características dizem respeito a questões de hegemonia e de poder no que estas implicam a manutenção de certo privilégio com relação ao acesso efetivo à cultura letrada de prestígio; a linguagem cifrada ou de certa forma inacessível à grande maioria da população; a iniciação, aqui no sentido da dificuldade da participação efetiva em determinados círculos, seja em nosso caso a própria 
dificuldade de acesso aos níveis superiores de escolarização. ${ }^{4}$ É nesse sentido que esses traços refletem a estrutura de poder presente em nossa sociedade. Queremos notar também que, em nosso entender, essa situação é típica de sociedades ainda pouco desenvolvidas do ponto de vista da organização da sociedade civil e das instituições democráticas, ou, em outros termos: o letramento restrito certamente comporta uma dimensão restrita de participação na sociedade em geral, algo para que talvez ainda não estejamos totalmente avisados.

Vamos nos deter brevemente nos pontos destacados acima. O recurso ao estilo formulaico, a aprendizagem de conteúdos memorizados de forma literal e a tendência ao preciosismo possuem íntima interrelação e mantêm, por sua vez, relação com a circulação restrita da cultura letrada pela sociedade como um todo. Esta questão se manifesta de diversas formas e dela temos mostras, por exemplo, na forma de funcionamento do mercado editorial, que produz mercadoria com acabamento e preços compatíveis apenas para uma pequena parcela da população. Há quem argumente que este fato se dá porque a população lê pouco - e nisso caímos em argumento circular, que culpa a população por seu próprio letramento restrito, em lugar de tentar o caminho contrário: será que se o material escrito fosse mais acessível, a população de fato leria tão pouco? Havendo pouco acesso à cultura letrada, esta tende a ser reproduzida de forma distante, ou, em outros termos, passa a ser cultuada por não ser devidamente cultivada. Certamente tudo isso tem a ver, também, com o real acesso à cultura letrada escolar, dentro da diferenciação destacada por Kalman (2004) entre disponibilidade e acesso: se hoje a escolaridade é extensiva, oferecida a praticamente toda a população brasileira - ou seja, se está disponível - será que está de fato totalmente acessível? E se não está, o que o impede?

Quanto aos modos orais de instrução, estão presentes na centralidade do professor enquanto o portador do conhecimento e na expectativa de que dele advenha o conhecimento a ser transmitido. A forma de instrução centrada na apresentação de conceitos e em sua definição - por exemplo, a definição do que sejam gêneros do discurso, ou do que seja coerência, do que seja coesão, e, aliás, não só do que seja

\footnotetext{
4 Entre outros dados, o Movimento "Todos Pela Educação" aponta para o fato sintomático de que "a cada dois minutos um aluno entre 15 e 19 anos deixa a escola". Informação disponível no sítio http://www.todospelaeducacao.com.br/. Acesso em: 8 jun. 2008.
} 
um substantivo, do que seja o Sujeito etc. - essa maneira de ensinar centrada em conceituações e centrada, por isso mesmo, na figura do professor e na expectativa de que ele seja capaz de repassar todos esses conceitos - essa forma de se conceber a educação é uma forma que pertence aos modos orais de instrução. 5 Também contém em si a mitificação - e a mistificação - da educação letrada, de sua infalibilidade, de sua invulnerabilidade: de seu mistério. A cultura letrada é vista dentro de uma aura semelhante àquela com que era ou ainda é tratada a religião em sua inacessibilidade.

Talvez isso explique, por exemplo, a situação em que uma senhora de meia-idade em processo de alfabetização, em classe de Mova, declarou certa vez em conversa com a pesquisadora que visitava sua classe: "Eu peço que Jesus abra minha cabeça para eu aprender a ler...”. 6 Entendemos que essa expectativa de uma solução divina estaria vinculada à aura que circunda a cultura letrada em nossa sociedade. Por outro lado, presenciamos muitas vezes a situação em que alunos de graduação da universidade pública estranham quando, em lugar de passar conceitos acabados na base do "isto é isso", "aquilo é aquilo", o professor faz referência a teorizações diversas e as compara, dentro de uma forma apropriada para o trabalho com a cultura letrada, onde o conhecimento se faz dentro dos livros, a partir de textos e de um saber acumulado nesse acervo. O professor deixa de ser, nesse caso, a referência de todo o conhecimento, e passa a cumprir o papel, nas palavras de Kleiman (2006), do "agente de letramento", alguém que pode mobilizar o conhecimento dos demais, que pode propiciar o contato com a cultura letrada, mas que já não é nem o centro, nem o portador preferencial do conhecimento.

Também podemos dizer, aliás, que uma das características dessa sociedade que ainda não é mais extensa e intensamente letrada é o próprio desconhecimento das leis escritas, seja por falta de disponibilidade, ou mesmo por acesso restrito a iniciados. Ainda a lei

\footnotetext{
5 Alertamos, aqui, para o fato de que esse viés centrado em conceituações e na suposição de que estas devam ser repassadas em sala de aula através da centralidade da figura do professor reapareceu nos documentos oficiais recentes (SÃO PAULO, 2008a-b).

6 Trata-se de sala de alfabetização de adultos do Projeto Mova/Brasil Alfabetizado de cidade de porte médio do interior paulista.
} 
escrita é aplicada de forma precária: não há garantias legais de sua aplicação, ela não é confiável.

$\mathrm{E}$ o que tudo isso tem a ver com nossa questão central neste momento, com a questão que diz respeito ao letramento do próprio professor? Como qualquer cidadão, o professor está em contato com a cultura que circula de forma predominante em sua comunidade: uma cultura letrada restrita, em nosso caso. Citaremos como exemplo o programa da TV Cultura "Nossa Língua Portuguesa", em que o professor Pasquale esclarece questões no que diz respeito ao uso cotidiano da Língua Portuguesa com seus presumidos acertos e desacertos, trazendo para a pauta aquelas características para as quais vimos apontando do letramento considerado hegemônico em nossa sociedade. No programa, a Língua Portuguesa é tratada com preciosismo e há a postulação implícita, já tantas vezes difundida e típica de uma sociedade em que o letramento é restrito - no sentido de que há um letramento privilegiado ao qual nem todos têm acesso - de que "o brasileiro não conhece sua língua”. Vale lembrar, aqui, que este é um tipo de presunção a todo o momento reforçado pela forma com que também as instituições privadas, de um modo geral, tratam o ensino de Língua Portuguesa em suas apostilas - uma forma que implica, com freqüência, o preciosismo e o estilo formulaico - enquanto, por outro lado, é mal vista a maneira que os lingüistas sugerem para o tratamento da língua materna - uma maneira advinda fundamentalmente de uma cultura letrada no que esta tem de apelo, não a mistificações, mas, ao contrário, a uma forma racional e objetiva de tratar a linguagem.

Os lingüistas, por sua vez, nessa sociedade ainda relativamente fechada, ora são acusados de quererem, como o poeta Bandeira, aceitar todos os barbarismos da língua, ora não são devidamente compreendidos, uma vez que numa cultura de letramento incipiente (e de democracia incipiente) ainda não pode ser bem aceita uma Gramática que propõe a liberdade, a maleabilidade, a flexibilidade. 7 Mais apropriada a nosso tipo de sociedade ainda parece ser a Gramática cheia de regras, de normatizações, uma Gramática que cerca a língua materna com uma aura de idealismo. Uma Gramática para iniciados.

\footnotetext{
7 "Abaixo os puristas/Todas as palavras sobretudo os barbarismos universais/ Todas as construções sobretudo as sintaxes de exceção/Todos os ritmos sobretudo os inumeráveis (BANDEIRA, 1976).
} 
Gostaríamos, ainda, de alertar que não se trata de investigar, apenas, as origens dessa gramática normativa e de suas prescrições, de vincular seu preciosismo à elite de épocas passadas que a teriam formulado; é importante percebermos de que forma e por que ela é ainda reforçada e, à sua maneira, se faz necessária nos protocolos que colaboram para a manutenção do poder na sociedade contemporânea. É como parte da microfísica do poder, no sentido foulcautiano da expressão (FOULCAULT, 1992), que a visão idealizada da Língua Portuguesa e o tradicionalismo de um modo geral, que ainda persistem na cultura escolar, não se fazem extirpar apenas por discursos vindos da academia ou das instâncias administrativas. Há uma luta mais ampla que diz respeito à democratização progressiva de nossa sociedade e que implica a ampliação do acesso às práticas letradas, sejam as vernaculares, sejam as escolares, pelos professores e, também, pela população como um todo.

Aproveitamos para fazer menção a alguns dados recentes com relação à precariedade da educação brasileira, uma publicada na Revista Veja, outra pelo movimento "Todos pela Educação".

A Revista Veja de 04/06/2008 traça a comparação entre o desempenho em educação no Brasil e aquele dos trinta países pertencentes à OCDE - Organização para a Cooperação e Desenvolvimento Econômico que envolve países como Alemanha, Estados Unidos, França, Portugal, Coréia do Sul, Eslováquia, Espanha. $\mathrm{O}$ artigo destaca:

Poucos fatores influenciam tanto o desempenho de um aluno em sala de aula quanto o nível de seu professor. Por essa razão, é especialmente preocupante o que mostra um levantamento recente feito com base no desempenho de 260000 professores em concursos públicos de quatro das maiores redes de ensino do país - Minas Gerais, Pernambuco, Rio de Janeiro e São Paulo: $73 \%$ deles foram reprovados em testes básicos das áreas em que pretendiam lecionar, entre elas matemática, português e física. Quase todos já dão aula em escolas públicas ou particulares. Boa parte dos $27 \%$ restantes, esses aprovados, passou raspando. $O$ resultado não é exatamente uma surpresa. Há pelo menos três décadas o padrão dos candidatos vem caindo e não é raro que nem todas as vagas sejam preenchidas no fim de um concurso desse tipo, como acontece mais uma vez agora. 
O articulista reconhece que há um problema que remete à formação dos professores:

O desastre revelado pelo novo levantamento é reflexo de dois problemas já antigos no Brasil. O primeiro diz respeito à qualidade dos cursos superiores de formação de professores, dos quais apenas $1 \%$ atinge a nota máxima na avaliação oficial. [...] Outra questão, igualmente preocupante, se deve ao fato de a carreira de professor não conseguir mais atrair os bons alunos. [...] O típico brasileiro que opta por ser professor de escola se enquadra justamente no primeiro caso, conforme reforçam dados de uma pesquisa da Unesco. Ele vem de família em que os pais não chegaram ao fim do ensino fundamental, estudou em colégio público e procura, antes de tudo, um vestibular mais fácil e um curso mais barato. ${ }^{8}$

Vale notar que, seja por uma certa tonalidade irônica e acusativa presente no artigo como um todo, seja pela falta de exploração de contingências mais amplas, o que sobra para o leitor é, mais uma vez, uma responsabilização do professor pelo estado das coisas na educação brasileira. Essa presunção, digamos de passagem, está também presente na própria política recentemente adotada pela Secretaria da Educação do Estado de São Paulo, ao publicar seus cadernos na tentativa de normatizar a prática pedagógica do professor, reforçando, com isso, a postulação repassada pela mídia de que o professor que está hoje na sala de aula possui formação insuficiente e tentando, implicitamente, formar melhor esse professor, como se pudesse caber às instâncias administrativas resolver esta questão através de cadernos pré-planejados a serem seguidos de forma compulsória pelos professores. Fica nítido, no caso, um jogo complementar entre poder e ideologia, na medida em que são passadas prescrições para o corpo docente e estas são reforçadas pela ideologia que circula pela mídia culpabilizando o professor pelo fracasso da educação na rede de ensino público estadual.

Sem pretender ver a problemática apenas sob o enfoque da macro-estrutura social, gostaríamos de alertar para uma dimensão mais ampla, que diz respeito ao contraste entre a disponibilidade de educação para todos e o efetivo acesso a essa educação, contraste este que,

\footnotetext{
${ }^{8}$ Os dois excertos estão disponíveis em: http://veja.abril.uol.com.br/040608/p_168.shtml. Acesso em: 7 jun. 2008.
}

MARTINS - Avanços e retrocessos nas propostas de ensino... 
conforme vimos destacando, traduz-se no letramento restrito próprio de nossa sociedade. Embora não explore essa questão, o próprio artigo da Revista Veja nos fornece pistas a esse respeito: grande parte dos professores que lecionam, hoje, nas escolas públicas é pertencente a famílias com baixo grau de escolaridade, ${ }^{9}$ freqüentou a escola pública que já passava por esse processo de sua própria reprodução e procurou as licenciaturas em instituições privadas por sentir-se excluído da possibilidade de concorrer a vestibulares de maior prestígio. A questão tem conotações hegemônicas e ideológicas, uma vez que, em lugar de se apontar para falhas no investimento público em educação, falhas históricas que resultaram na situação calamitosa atual, é o professor que é culpado por seu fracasso, assim como, de resto, é o aluno ou o adulto em processo de alfabetização que costumam ser responsabilizados pelo fato de terem abandonado a escola precocemente.

O Movimento "Todos pela Educação" - que abrange diversos setores da sociedade civil brasileira em luta conjunta pela melhoria da educação - publicou o dado de que 3\% de jovens e crianças brasileiras entre sete e catorze anos estão fora da escola, o que representa 800.000 brasileiros; também aquele de que menos de $5 \%$ das crianças que freqüentam a quarta série do Ensino Fundamental estão plenamente alfabetizadas. São dados que já não podem ser vistos do ponto de vista da falta de iniciativa dos cidadãos ou dos pequenos cidadãos, mas que remetem, de preferência, a questões de poder, que se vinculam, por sua vez, de forma íntima, com as questões ideológicas de mascaramento desse poder.

\section{DA GRAMÁTICA, DAS IDEALIZAÇÕES E DA IDEOLOGIA}

Estamos tentando defender que o tradicionalismo que reconhecemos na escola é sintoma do tradicionalismo que nem sempre enxergamos em nossa sociedade e que, por sua vez, está relacionado com a democratização incipiente de nosso país em termos de falta de organização da sociedade civil e de falta de acesso generalizado aos bens

\footnotetext{
9 Lembramos que em "Ways with words", Heath (1983) explora a forma com que o letramento de uma geração interfere na possibilidade de inserção da geração seguinte nas práticas letradas de prestígio.
} 
culturais. Que a gramática tradicional ainda praticada com tanta freqüência nas escolas é continuidade da gramática - em sentido amplo, ou seja, no sentido das regras e protocolos sociais exigidos e praticados em diversos graus na vida cotidiana - presente de forma difusa em nossa sociedade, fora dos muros da escola. Que um programa como "Nossa Língua Portuguesa" é em parte um difusor dessa cultura gramatical e dessa idealização tradicional, mas em parte, também, a manifestação dessa gramática entranhada na sociedade. Que essa gramática está entranhada de forma bem mais profunda e que não se restringe apenas às normatizações da linguagem, mas a uma série de idealizações próprias de uma exigência maior que atravessa toda a sociedade e que confere ao letramento de prestígio uma aura de superioridade intimamente relacionada ao estatuto hegemônico de que parecem desfrutar seus portadores. Lembramos, ainda, que essa gramática de viés sociológico e antropológico - em termos de padrões que atravessam a sociedade na forma de idealizações - é também, em certo sentido, a mesma que se faz presente nas ambientações higienizadas das novelas televisivas, no corpo escultural de atores, de atletas, dos personagens presentes nas diversas propagandas. Padrões que estão presentes também de forma difusamente normativa nas sociedades ditas avançadas, porém é de se supor que o acesso mais generalizado a uma diversidade maior de práticas letradas complexas traga consigo a possibilidade de uma postura de objetivação crítica quanto a essas idealizações. ${ }^{10}$

É dos sociolingüistas o mérito de ter desmistificado a norma padrão e de ter mostrado que os diversos dialetos sociais são portadores de uma gramática e de uma racionalidade igualmente válida. Mas essa defesa ainda permanece, ao menos em parte, restrita aos círculos acadêmicos e está insuficientemente difundida no âmbito social mais amplo. Por outro lado, a gramática que Franchi postula, a gramática das manipulações lingüísticas, da brincadeira com a linguagem, embora tenha a ver, por princípio, com a espontaneidade do uso de uma língua, ou seja, com seu uso real e cotidiano, é, enquanto concepção teórica, excessivamente acadêmica para que possa adquirir confiabilidade dentro

\footnotetext{
10 Vale lembrar, aqui, a desconfiança, de Adorno (2003), com relação à efetiva possibilidade de emancipação do ser humano. De toda forma, o filósofo aponta para a necessidade de diversificarmos as experiências de aprendizagem: de ampliar e diversificar o currículo escolar em todos os níveis, como forma de propiciarmos essa emancipação.
}

MARTINS - Avanços e retrocessos nas propostas de ensino... 
dos círculos em que ainda se prioriza o conhecimento conceitual e decorado.

Quando alguns pedagogos defendem a ênfase nas competências e não no conhecimento centrado em conteúdos - eles estão também, à sua maneira, tentando apontar para um outro tipo de cultura. O que percebemos, nesse caso, no entanto, é uma outra característica das sociedades tradicionais em que predomina o letramento restrito: aquela da persistência de resíduos orais na cultura letrada, uma vez que se propugna, por um lado, a ênfase nas competências, porém, por outro, continua a valer o estilo formulaico, dentro de um processo de hibridização, de bricolagem, que envolve a mistura de elementos de culturas diferentes, haja vista a discrepância entre o que defendem os PCNs, por exemplo, e a forma de avaliação dos exames oficiais, como Saresp, Saeb e mesmo os diversos vestibulares das universidades públicas. Vejam-se, também, os recentes jornais de revisão em que os estudantes das escolas públicas conviveram com frases que aludiam a competências e, simultaneamente, com questões gramaticais tradicionais de preenchimento de lacunas ou de múltipla escolha.

\section{DA MALEABILIDADE DOS GÊNEROS DO DISCURSO E DAS NOVAS PADRONIZAÇÕES}

Entendemos, ainda, que aquela dificuldade inerente a uma condição incipiente de letramento e difusa na sociedade como um todo, conforme vimos argumentando, tem também se manifestado na forma de aplicação ao ensino de Língua Portuguesa da conceituação a respeito dos gêneros do discurso, uma vez que, mais uma vez, tende-se a priorizar as conceituações metalingüísticas, em lugar do trabalho com a linguagem propriamente dita ou com a produção textual enquanto prática discursiva.

É dentro dessa linha de proposta pedagógica que os "Cadernos do Professor" (SÃO PAULO, 2008a) apresentam as seqüências didáticas em que se pressupõe que certos gêneros do discurso sejam tematizados e trabalhados em cada nível de ensino, a partir do enfoque de alguns exemplares de textos considerados como representantes típicos de determinado gênero ou de determinada tipologia textual, ou seja: 
novamente, trabalha-se com padronizações, com idealizações. Há pouca ou nenhuma sugestão que aponte para o que se tem defendido, no mínimo já há vinte e cinco anos, no que diz respeito à aprendizagem significativa, inserida em situações reais de uso da linguagem. Tudo o que os pequenos cadernos trazem é a sugestão para que os alunos discutam certas temáticas entre si em sala de aula, ou que façam certo levantamento junto à comunidade a que pertencem - o que é absolutamente insuficiente para caracterizar minimamente uma prática de letramento genuína, ou o que podemos entender como um projeto de letramento escolar.

Vamos nos deter, a título de exemplo, na análise do "Caderno do Professor" (SÃO PAULO, 2008b) elaborado para ser aplicado na sexta série do Ensino Fundamental durante o $1^{\circ}$ bimestre letivo do ano de 2008. O caderno apresenta cinco assim chamadas propostas de Situações de Aprendizagem, absolutamente desvinculadas de qualquer objetivo social mais amplo que apontasse para o que temos denominado aprendizagem significativa. São elas:

- estudo dos traços característicos do agrupamento tipológico "relatar" (1)

- estudo dos traços característicos do agrupamento tipológico "relatar" (2)

- estudo de algumas diferenças entre a linguagem oral e a linguagem escrita

- estudo da estrutura do jornal

- estudo da notícia no jornal

É certo que a orientação que aparece a título de introdução geral parece pressupor, de início, essa tendência, mas logo se trai ao apontar para uma dimensão bastante restrita da compreensão a respeito da inserção em práticas letradas:

A escola tem vários compromissos e responsabilidades na formação de seus alunos como cidadãos comprometidos e atuantes. No que tange ao ensino de língua, contribuindo essa formação, é preciso saber lidar, lingüística e socialmente, com os textos nas situações reais em que circulam, porque assim é 
possível favorecer o desenvolvimento de habilidades que permitam ao estudante circular pelos variados contextos de uma sociedade letrada: os textos fazem sentido e tornam-se parte da vida do aluno quando são inseridos nas mais diversas situações comunicativas, como objeto do e como meio para o conhecimento.

Nesse sentido, é importante pensar o ensino de língua como uma inserção nas questões do letramento, o qual será determinado pela variedade de gêneros textuais que a criança ou adulto reconhece. (SÃO PAULO, 2008b, p. 8)

Lembramos que, segundo Kleiman (2005), uma prática de letramento pode implicar, por exemplo, o envio de uma carta ou a escrita de um diário, enquanto atividades que envolvem a língua escrita e que comportam objetivos determinados em situações determinadas. Já um projeto de letramento representaria, segundo Kleiman (2000, p. 238):

[...] um conjunto de atividades que se origina de um interesse real na vida dos alunos e cuja realização envolve o uso da escrita, isto é, a leitura de textos que, de fato, circulam na sociedade e a produção de textos que serão lidos, em um trabalho coletivo de alunos e professor, cada um segundo sua capacidade. O projeto de letramento é uma prática social em que a escrita é utilizada para atingir algum outro fim, que vai além da mera aprendizagem da escrita (a aprendizagem dos aspectos formais apenas), transformando objetivos circulares como 'escrever para aprender a escrever' e 'ler para aprender a ler' em ler e escrever para compreender e aprender aquilo que for relevante para o desenvolvimento e realização do projeto.

Esta é, de resto, a abordagem das práticas de letramento que condiz com os assim chamados "Estudos do Letramento" e com seu enfoque sócio-histórico, assim como, também, com o enfoque bakhtiniano dos gêneros do discurso, que os postula de forma intimamente relacionada com determinadas esferas da atividade humana. Dessa forma, referir-se ao letramento do ponto de vista da "variedade de gêneros textuais que a criança ou adulto reconhece" aponta para enorme reducionismo teórico que certamente comporta conseqüências didáticas consideráveis. É, nesse sentido, nítido o enfoque circunstancial do contexto presente nos "Cadernos do Professor" de Língua Portuguesa. 
Sugere-se, por exemplo, como forma de dar início à primeira Situação de Aprendizagem: "Em uma conversa informal com uma pessoa mais velha (da família, vizinho ou amigo), os estudantes devem registrar em seu caderno algum fato importante que aconteceu na vida dessa pessoa quando ainda era criança" (SÃO PAULO, 2008b, p. 13).

É digno de nota o fato de que, apesar de, em certo sentido, a proposta pedagógica apontar para um trabalho que transcende os muros da escola, esse transcender é excessivamente circunstancial e não traz grandes novidades em relação às lições de casa em que, no passado, os estudantes eram chamados a trazer, para a sala de aula, resultados de alguma pesquisa desenvolvida e acompanhada de anotações no caderno escolar. Estamos muito longe da possibilidade de praticar a linguagem, reconhecida como pertencente a certos gêneros do discurso, enquanto atividade genuinamente ancorada em situações de produção, sejam escolares ou não, e, por isso mesmo, sujeita a manipulações, a distorções, a inovações. A tipologia textual aparece de forma relativamente estabilizada e sentimo-nos bem próximos dos tradicionais exercícios de interpretação e de produção de textos de mais de trinta anos atrás, apenas com uma roupagem ligeiramente diferente e com a assimilação canhestra de uma nomenclatura mais atualizada.

\section{CONSIDERAÇÕES FINAIS}

Discutimos, no decorrer deste trabalho, a forma com que as recentes diretrizes de ensino presentes nos "Cadernos do Professor" publicados pela Secretaria da Educação do Estado de São Paulo representam um retrocesso histórico quando comparadas com propostas e diretrizes curriculares de vinte ou trinta anos atrás. Apontamos, também, para a maneira com que o letramento do professor é parte do letramento que permeia a sociedade brasileira como um todo, com seus componentes de poder e de ideologia que tenta mascarar esse poder, atribuindo ao professor ou aos estudantes toda a responsabilidade por não conseguirem ultrapassar as barreiras do poder estabelecido.

Entendemos que a análise crítica que leva em consideração o contexto social em sentido amplo nos permite desvendar componentes que dizem respeito à estruturação social e, dessa forma, dar conta de 
certos vetores que, estando presentes na sociedade de forma difusa, influem, também, seja na atuação do professor em sala de aula, seja na maneira com que se efetiva o diálogo entre as instâncias administrativas e o corpo docente, ou entre o círculo acadêmico e as instituições escolares.

\section{REFERÊNCIAS}

ADORNO, T. W. Educação e emancipação. São Paulo: Paz e Terra, 2003. BAKHTIN, M. Estética da criação verbal. São Paulo: Martins Fontes, 1997. BANDEIRA, M. Estrela da vida inteira. Rio de Janeiro: José Olympio, 1976. BRASIL. Ministério de Educação e Cultura. Guias Curriculares Nacionais. Brasília: MEC, 1975.

. Ministério da Educação e do Desporto. Parâmetros Curriculares Nacionais - Língua Portuguesa $-3^{\circ}$ e $4^{\circ}$ ciclos. Brasília: MEC, 1998.

COLLINS, J.; BLOT, R. Literacy and literacies: text, power and identity. Cambridge: Cambridge University Press, 2005.

FAIRCLOUGH, N. Discurso e mudança social. Brasília: Editora da UNB, 2001.

FOUCAULT, M. Microfísica do poder. Rio de Janeiro: Graal, 1992.

GOODY, J. Literacy in traditional societies. Cambridge: Cambridge University Press, 1968.

HEATH, S. B. Ways with words: language, life and work in communities and classrooms. Cambridge: Cambridge University Press, 1983.

KALMAN, J. Saber lo que es la letra: una experiencia de lectoescritura con mujeres de Mixquic. Mexico: Siglo Veintiuno, 2004.

KLEIMAN, A. B. O processo de aculturação pela escrita: ensino da forma ou aprendizagem da função? In: ; SIGNORINI, I. (Orgs.). O ensino e a formação do professor: alfabetização de jovens e adultos. Porto Alegre: Artmed, 2000.

. Preciso "ensinar" o letramento? Não basta ensinar a ler e a escrever? CEFIEL/IEL/UNICAMP; BRASIL. Ministério da Educação. Linguagem e letramento em foco. Linguagem nas séries iniciais. Brasília: MEC, 2005. 
. Processos identitários na formação profissional. O professor como agente de letramento. In: CORREA, M.; BLOCH, F. (Orgs.). Ensino de língua: representação e letramento. Campinas: Mercado de Letras, 2006.

OLSON, D. R. O mundo no papel: as implicações conceituais e cognitivas da leitura e da escrita. São Paulo: Ática, 1997.

SÃO PAULO (ESTADO). Secretaria da Educação. CENP. Proposta curricular para o ensino de língua portuguesa $-1^{\circ}$ grau. São Paulo: SE/CENP, 1986.

Secretaria da Educação. CENP. Criatividade e gramática. São Paulo: SE/CENP, 1988.

. Secretaria da Educação. Caderno do Professor. Língua portuguesa: ensino fundamental. São Paulo: SEE, 2008a.

Secretaria da Educação. Caderno do Professor. Língua portuguesa: ensino fundamental - sexta série do $1^{\circ}$ bimestre. São Paulo: SEE, 2008b.

SCHNEUWLY, B. Gêneros e tipos de discurso: considerações psicológicas e ontogenéticas. In: SCHNEUWLY, B.; DOLZ, J.; e colaboradores. Gêneros orais e escritos na escola. Campinas, SP: Mercado de Letras, 2004.

; DOLZ, J. Os gêneros escolares - Das práticas de linguagem aos objetos de ensino. In: ; e colaboradores. Gêneros orais e escritos na escola. Campinas, SP: Mercado de Letras, 2004.

STREET, B. (Ed.). Cross-cultural approaches to literacy. Cambridge: Cambridge University Press, 1993.

Recebido em 16/08/08. Aprovado em 23/09/08.

Title: Advances and setbacks in the guidelines for Portuguese teaching: issues of ideology and power

Author: Maria Sílvia Cintra Martins

Abstract: In this paper I point out issues of ideology and power whose influence we are seldom aware of, although they are always present in everyday classroom contexts. My main objective is to call attention to the vectors that exert pressure on the teachers' performance. To do so, I analyse the different Brazilian official guidelines for the teaching of Portuguese, and discuss the way the recent guidelines adopted in the State of São Paulo, in the form of "Teachers' Notebooks", represent a historical set back due to certain ideological and hegemonic aspects present in these materials.

Keywords: mother tongue; teaching; power; ideology. 
Titre: Progrès et rétrogradation dans les propositions d'enseignement de langue portugaise: questions d'idéologie et de pouvoir

Auteur: Maria Sílvia Cintra Martins

Résumé: On attire l'attention dans cet article aux questions d'idéologie et de pouvoir dont l'influence souvent on ne se rend pas compte, même si elle est toujours présente dans les contextes du quotidien de salles de classe, en les croisant. On a comme objectif principal celui d'attirer l'attention vers les conducteurs qui exercent pression sur le rôle du professeur. On s'arrête dans des considérations sur les différents guides curriculaires pour l'enseignement de Langue Portugaise. On discute à propos de la forme des directrices adoptées par la Secretaria da Educação do Estado de São Paulo, dans les "Cahiers du Professeur", qui représentent une rétrogradation historique en fonction de certains composants idéologiques et hégémoniques qu'ils comportent.

Mots-clés: langue maternelle; enseignement; pouvoir; idéologie; travail; enseignement.

Título: Avances y retrocesos en las propuestas de enseño de lengua portuguesa: cuestiones de ideología y de poder

Autor: Maria Sílvia Cintra Martins

Resumen: Llamamos en este artículo la atención para las cuestiones de ideología y de poder de cuya influencia frecuentemente no nos damos cuenta, aunque estén siempre presentes en los contextos cotidianos de aula, atravesándolos. Tenemos como principal objetivo alertar para los vectores que ejercen presión sobre la actuación del profesor. Nos detenemos en consideraciones al respecto de las diferentes guías curriculares para el enseño de Lengua Portuguesa. Discutimos de que forma las directrices recientes adoptadas por la Secretaría de Educación del Estado de São Paulo, en la forma de los "Cuadernos del Profesor", representan un retroceso histórico en función de ciertos componentes ideológicos y hegemónicos que comportan.

Palabras-clave: lengua materna; enseño; poder; ideología; trabajo; docencia. 